DOI: $10.22481 /$ recuesb.v8i14.7827

\title{
PERCEPÇÕES E COMPORTAMENTO FINANCEIRO DE ALUNOS DO ENSINO MÉDIO DO VALE DO TAQUARI - RS
}

\section{PERCEPTIONS AND FINANCIAL BEHAVIOR OF HIGH SCHOOLS STUDENTS OF THE TAQUARI VALLEY - RS}

\author{
Carla Rafaela Griebeler ${ }^{1}$ \\ Eloni José Salvi ${ }^{2}$ \\ Samuel Martim de Conto ${ }^{3}$
}

\begin{abstract}
Resumo: O presente artigo buscou identificar o comportamento e o conhecimento dos alunos do Ensino Médio da região do Vale do Taquari/RS em relação às Finanças Pessoais. Os resultados da pesquisa são consequência de levantamento realizado em 2017, durante a realização de cursos sobre finanças pessoais, um projeto desenvolvido pelo Centro de Gestão Organizacional, da Universidade do Vale do Taquari, de Lajeado-RS. Após o levantamento por meio de survey cross-sectional referente à percepção dos alunos participantes dos cursos, os questionários foram tabulados e serviram para análises e considerações a respeito da temática. Constatou-se, dentre outros aspectos, que a maior parte dos respondentes já possui algum rendimento, entretanto, apenas um quarto realiza algum controle sobre seus recursos financeiros e apenas um terço planeja seu futuro. $O$ trabalho constatou, ainda, que as escolas, em sua grande maioria, não abordam a temática e que o curso de Finanças Pessoais impacta positivamente no comportamento financeiro dos entrevistados.
\end{abstract}

Palavras-chave: Controle. Educação Financeira. Finanças Pessoais. Orçamento e investimento.

Abstract: This article aimed to identify the behavior and knowledge on Personal Finance of high school students in the Taquari Valley/RS region. The results are from a survey conducted in 2017, during courses on personal finance, a project developed by the Center for Organizational Management of the University of Vale do Taquari - Univates, Lajeado-RSBrazil. After a cross-sectional survey regarding the perception of the students participating in the courses, the questionnaires were tabulated and used for analyzes and considerations on the subject. It was found that, among other aspects, most respondents already have some income, however, only a quarter have some control over their financial resources and only a third plan their future. The study also found that the majority of schools do not approach the subject and that the Personal Finance course has a positive impact on the financial behavior of the interviewees.

Keywords: Control. Financial Education. Personal Finances. Budget and investment.

\footnotetext{
${ }^{1}$ Graduando em Ciências Contábeis, pela Universidade do Vale do Taquari (Univates), Rio Grande do Sul, Brasil. E-mail: carla.griebeler@universo.univates.br

${ }^{2}$ Mestre em Administração. Professor da Universidade do Vale do Taquari (Univates), Rio Grande do Sul, Brasil. E-mail: esalvi@universo.univates.br

${ }^{3}$ Doutor em Administração. Professor Universidade do Vale do Taquari (Univates), Rio Grande do Sul, Brasil. E-mail: samuelc@univates.br
} 


\section{Introdução}

No Brasil, a grande maioria das pessoas e famílias encontra-se, normalmente, com endividamento e sem reservas financeiras. O endividamento médio das famílias brasileiras, em fevereiro de 2017, segundo a Confederação Nacional do Comércio de Bens, Serviços e Turismo (CNC, 2017), foi de 56,2\%, e deste 76,8\% referem-se ao cartão de crédito, que possui uma das taxas de juros mais altas do mercado. Embora o endividamento seja menor do que os 60,8\% de um ano atrás, o percentual dos que declaram não ter condições de pagar as dívidas subiu de 8,6\% em 2016, para 9,8\% em 2017.

Quanto às reservas financeiras, o cenário não é o melhor, segundo estudos do Serviço de Proteção ao Crédito (SPC BRASIL, 2017), cerca de 65\% dos brasileiros não possuem reservas financeiras, e este indicador é ainda pior quando se trata das classes menos favorecidas (C, D, e E), das quais pouco mais de $10 \%$ fazem reservas financeiras. Independente do padrão de formação e de renda, há um grande contingente de pessoas com baixo conhecimento em finanças, o que as coloca frequentemente em apuros por falta de gestão desses recursos. Meneghetti Neto (2014, n.p.) afirma que "os consumidores com formação e renda elevada podem ser tão ou mais ignorantes das questões financeiras do que as pessoas com menor renda e formação".

Porém, as finanças fazem parte do cotidiano e, por isso, têm impacto em qualquer decisão que se tome em relação ao futuro. Enquanto que nas pequenas decisões do dia-a-dia, como tomar café na padaria, o grau de dificuldade da decisão financeira é pequeno, nas questões que envolvam compra de um imóvel ou de um carro, por exemplo, exigem uma análise aprofundada dos impactos financeiros, pois estas decisões trazem efeito inclusive nas decisões que são tomadas diariamente (GODOY et al., 2006).

As ações para a formação de crianças e jovens neste tema já vem sendo desenvolvidas há algum tempo, como no caso do projeto experimental da Secretaria de Educação Básica (SEB), do Ministério da Educação, através do Grupo de Apoio Pedagógico (GAP) que, de 2008 a 2010, promoveu a Educação Financeira na Rede Pública de Ensino Médio nos estados do Ceará, Minas Gerais, Rio de Janeiro, São Paulo, Tocantins e do Distrito Federal, com resultados animadores (BRUHN et al., 2017). Porém, carecemos de programas continuados e abrangentes de formação em educação financeira em todos os níveis educacionais.

Na região do Vale do Taquari/RS, o projeto de extensão em Educação Financeira da 
Univates, da Universidade do Vale do Taquari, já atendeu desde 2010 aproximadamente 8.000 alunos de Ensino Médio, por meio da realização de oficinas presenciais nas escolas, tendo como objetivo introduzir a temática Educação Financeira Pessoal aos alunos da educação básica do Vale do Taquari.

Diante disso, o presente trabalho buscou compreender os hábitos financeiros de alunos de Ensino Médio de escolas públicas e privadas do Vale do Taquari-RS. Durante o ano de 2017, foi aplicado um questionário com perguntas estruturadas, abrangendo aspectos inerentes às finanças pessoais, como poupança, controle, investimentos, gastos, etc. O objetivo foi identificar o comportamento e o conhecimento dos alunos do Ensino Médio da região do Vale do Taquari/RS em relação às finanças pessoais.

Para atingir ao objetivo proposto, este artigo está organizado em três seções, além desta introdução e das conclusões. Na primeira sessão, consta o referencial a respeito de finanças pessoais e educação financeira, seguido pela segunda sessão, onde são detalhados os procedimentos metodológicos utilizados e na terceira sessão, são apresentados os resultados e as discussões do levantamento realizado.

\section{Finanças pessoais e educação financeira}

As técnicas de gestão financeira, quando são aplicadas em indivíduos e famílias, formam as chamadas finanças pessoais. De acordo com Pires (2006, p. 13) "as finanças pessoais têm por objeto de estudo e análise as condições de financiamento das aquisições de bens e serviços necessários à satisfação das necessidades e desejos individuais". Desse modo, as finanças pessoais podem ser definidas, segundo Cherobim e Espejo (2011. p. 1) como:

\footnotetext{
[...] ciência que estuda a aplicação de conceitos financeiros de uma pessoa ou família. Em finanças pessoais são considerados os eventos financeiros de cada indivíduo, bem como sua fase de vida para auxiliar no planejamento financeiro. Estudos de opções de financiamento, orçamento doméstico, cálculos de investimentos, gerenciamento de conta corrente, planos de aposentadoria, acompanhamento de patrimônio e acompanhamento de gastos são todos exemplos de tarefas associadas a finanças pessoais. (CHEROBIM; ESPEJO, 2011, p. 1)
}

Sendo assim, as finanças pessoais são o conjunto de táticas utilizadas por uma pessoa ou por uma família com o objetivo de atender as necessidades e desejos. Tanto as empresas quanto as pessoas possuem necessidades, objetivos e ambos estão sujeitos a uma dinâmica 
financeira similar. As pessoas recebem dinheiro em forma de salário e as empresas recebem dinheiro através da venda de produtos ou de serviços. As grandes diferenças das finanças das empresas e das finanças pessoais são o fator humano e a alavancagem. A primeira, está muito mais evidente nas finanças pessoais, já que as decisões carregam fatores emocionais, crenças, culturas, o que não acontece nas finanças de uma empresa, em que os gestores tomam decisões objetivas. Já a alavancagem, corresponde utilizar dinheiro emprestado (de terceiros) com a finalidade de aumentar o valor e o lucro, o que pouco acontece nas famílias, já que o dinheiro emprestado é utilizado em bens que sofrem desvalorização e depreciam (MASSARO, 2015).

Com o ambiente econômico um pouco mais estável, a oferta de produtos e serviços financeiros, como o crédito, teve aumento e, consequentemente, o poder de consumo dos brasileiros e os índices de endividamento também cresceram. O índice de famílias brasileiras endividadas em fevereiro de 2017, segundo a CNC (2017) foi de 56,2\% e em agosto do mesmo ano, cerca de 74,4\% das famílias gaúchas possuíam dívidas, de acordo com Pesquisa de Endividamento e Inadimplência do Consumidor do Rio Grande do Sul (PEIC-RS, 2017). Este alto percentual demonstra que, ainda que todos lidem cotidianamente com dinheiro, são poucos os que se dedicam a buscar informações para gerir melhor seus recursos financeiros, e desta forma, o número de pessoas endividadas aumenta significativamente a cada mês. Nesse sentido, segundo Savoia:

\begin{abstract}
O governo, incapaz de poupar e realizar os investimentos propulsores do crescimento, procurou, nos últimos anos, ampliar a oferta de crédito, para incentivar o consumo de bens e serviços e, assim, aumentar a produção. No entanto, o consumo das famílias não consegue, sozinho, estimular os investimentos, que geram empregos e elevação da renda. Para agravar esse quadro, a população, despreparada para dimensionar o volume de comprometimento do seu orçamento, avança com ímpeto ao crédito fácil e, endividada, busca caminhos para restaurar o seu equilíbrio. $O$ crescimento desorientado do crédito produz a inadimplência. A partir daí, os empréstimos são interrompidos e a economia reduz a sua atividade. Como consequência dessas ações, surge um círculo vicioso de expansão e retração do crescimento. (SAVOIA et al., 2007, n. p.)
\end{abstract}

Para Domingos (2011), o problema do endividamento não se restringe ao Brasil, mas sim no mundo todo, onde as economias desequilibradas refletem a falta de preparo individual na gestão com responsabilidade das finanças pessoais. Devido a isso, a educação financeira tornou-se uma preocupação em diversos países, que viram sua população com parte da renda comprometida com dívidas e juros altos. Assim, surgiram também estudos sobre o tema, para a criação de programas visando à instrução da população. Um exemplo desta preocupação em outros países é abordado por Andersson (2016), ao relatar as dificuldades que os portugueses 
têm em gerenciar seus recursos financeiros. Entre os benefícios da educação financeira estão o equilíbrio das finanças pessoais, o bom uso do sistema financeiro, menor possibilidade de fraudes, realização de sonhos, preparo para imprevistos, bem como para a aposentadoria. A educação financeira é uma ferramenta que promove o desenvolvimento econômico de um país, e influencia a economia em um todo, pois está ligada aos níveis de endividamento e de inadimplência das pessoas e a capacidade de investimento dos países (BCB, 2013).

Portanto, a educação financeira deve ser abordada na escola, pois, assim, os jovens que sairão do sistema escolar possuirão um conhecimento amplo das questões financeiras que os auxiliarão a gerir corretamente suas finanças ao longo de suas vidas (MENEGHETTI NETO, 2014 , n. p.). É nesse sentido que quanto mais precoce a temática seja abordada para a população, maiores serão as possibilidades de que as pessoas consigam lidar com seus recursos financeiros.

\section{Orçamento e planejamento financeiro}

Mesmo ainda pequenas, convivemos com várias situações ligadas ao dinheiro, mas para se tirar melhor proveito dele, é necessário utilizar o dinheiro da forma mais favorável, já que ele é um recurso limitado. O aprendizado e a prática dos conhecimentos de educação financeira contribuem na melhor gestão das finanças pessoais, assim tornando as vidas mais tranquilas e equilibradas sob o ponto de vista financeiro (BCB, 2013).

De acordo com Luquet e Assef (2007, p. 14), “o relacionamento com o dinheiro é um dos maiores desafios da humanidade". Ele é fundamental para o atendimento das necessidades humanas e deve ser gasto de forma planejada e correta, já que os indivíduos são expostos às diversas tentações de compra e os gastos desnecessários devem ser evitados. Nessa perspectiva, conforme Ferreira:

\footnotetext{
Dinheiro e tempo são algumas das principais variáveis que compõem o universo abordado pela matemática financeira em suas várias modalidades de atuação. Pois, partindo-se do princípio essencial de se saber como o dinheiro funciona e se capitaliza, pode-se descobrir a chave e a compreensão de como empregá-lo de forma mais lógica e produtiva, para gerar mais retornos quantitativos e qualitativos em termos de bemestar social, econômico privado e pessoal. (FERREIRA, 2008, p. 2)
}

O planejamento financeiro possui muitas definições, entretanto, a maioria dos autores concorda que o planejamento é uma ferramenta de gestão, que contém etapas fundamentadas 
de algum objetivo, visando concretizar uma meta. De acordo com o Comitê Nacional de Educação Financeira:

\begin{abstract}
Um orçamento doméstico ou pessoal é uma ferramenta financeira, geralmente uma tabela na qual em um dos lados entra quanto você ganha (receitas) e no outro, quanto você gasta (despesas). Muitas pessoas fazem orçamentos com a intenção de reduzir seus gastos. Essa é uma das funções de um orçamento, mas não é a única. Um orçamento é um instrumento para que você possa ter maior controle sobre sua vida financeira e, a partir daí, planejar para alcançar suas metas. (CONEF, 2013, p. 28)
\end{abstract}

Devido a isso, o planejamento e o orçamento financeiro são fundamentais para conhecer a realidade financeira de cada família, escolher projetos e também para administrar imprevistos como o desemprego, o estrago de alguma peça do carro e outros fatos que podem acarretar em uma dívida (BCB, 2013). O planejamento financeiro diz respeito à "organização geral" das finanças, controle e conhecimento do fluxo financeiro (entradas e saídas de dinheiro), e alinhamento dos recursos financeiros com os objetivos e as aspirações de vida do indivíduo ou família (MASSARO, 2015, p. 31).

Para Gitmann (2001, p. 43) o planejamento financeiro é muito importante para as operações tanto das empresas como das famílias, "pois ele mapeia os caminhos para guiar, coordenar e controlar as ações das empresas e das famílias para atingir seus objetivos". E, ainda, nesse contexto Meneguetti Neto assinala que:

Guardar dinheiro por guardar, não é a melhor e mais acertada das razões para a acumulação de patrimônio para usufruir de conforto e segurança no longo prazo. É importante, inicialmente, definir objetivos para sua vida financeira. Objetivos específicos, que possam ser mensurados e sobretudo que possam ser atingidos. (MENEGUETTI NETO, 2014, n. p.)

As planilhas são um exemplo de planejamento familiar ou pessoal, há muitos exemplos de planilhas de orçamento, porém a mais adotada, segundo Luquet e Assef (2006), separa os gastos em três tipos:

a) fixos: aqueles que têm o mesmo montante todo mês;

b) variáveis: as contas que são pagas todo mês, mas que podem ter valores diferentes, como por exemplo, a luz e o telefone;

c) arbitrários: são os gastos que não são necessários em todos os meses, como comprar roupas, ir ao cinema, etc.

Por fim, de acordo com Andersson (2016), todos sabemos aproximadamente quanto 
ganhamos e também quanto gastamos, mas, sempre corremos o risco de sermos surpreendidos por eventuais despesas nas ocasiões menos indicadas e, por isso, é importante fazer um orçamento e levá-lo a sério.

\section{Investimentos}

Estamos sujeitos às situações imprevistas, como incêndio de uma casa ou o roubo de um carro, para nos prevenirmos do impacto que acontecimentos desse tipo podem ter em nossas vidas, como ficar sem casa, carro ou outros infortúnios, precisamos cuidar do que temos, criar estratégias de proteção do nosso patrimônio. Além disso, o mercado de trabalho se encontra cada vez mais incerto, desta maneira, vê-se a necessidade dos jovens se envolverem mais com a economia e passarem a guardar uma parcela do seu dinheiro para o futuro.

O adolescente ainda é muito otimista em relação ao seu futuro, mesmo com essa incerteza vinda do mercado mundial. Por isso, mudar a mentalidade desses jovens é uma atitude necessária e fará com que eles se envolvam mais com a economia, através da leitura de jornais, revistas, entre outros. Assim, duas atividades são vitais para os adolescentes, que são: controlar as despesas e fazer poupança. A primeira é basicamente gastar menos do que se ganha e a segunda, fazer poupança, propiciará aos jovens se prepararem para desafios futuros (MENEGHETTI NETO, 2014).

De acordo com Cherobim e Espejo (2011, p. 93), "não basta apenas guardar dinheiro, é preciso guardar dinheiro em produtos financeiros que proporcionem segurança e rentabilidade". No mesmo sentido, Godoy et al. (2006) afirmam que o investimento é uma parte que compõe o planejamento financeiro, mas pode ser tratado em separado, sendo considerado o resultado positivo de um planejamento financeiro correto, devido sua abrangência e importância.

Para Gitman e Joehnk (2005), um investimento é um instrumento em que são depositados fundos com a expectativa de que estes gerarão renda positiva e/ou preservarão ou aumentarão o valor. Um investimento possui três características: liquidez, risco e rentabilidade. Segundo o BCB (2013), essas características podem ser definidas como:

a) liquidez: trata da capacidade do investimento ser transformado em dinheiro a qualquer momento e por um preço justo; 
b) risco: é o oposto de segurança, ou seja, o quão provável serão as perdas. Determinados tipos de investimentos podem fazer com que pequenos ou grandes valores sejam recebidos ou perdidos;

c) rentabilidade: pode ser definida como o retorno, a remuneração do investimento.

As aplicações financeiras podem ser feitas em produtos chamados de "papéis", "aplicações" ou "títulos". Estes, podem ser classificados em investimento de renda fixa ou de renda variável (Quadro 1). A principal diferença entre os dois é que, enquanto no investimento de renda fixa, a rentabilidade é preestabelecida entre as partes, nas aplicações de renda variável, a rentabilidade é incerta e, por isso, normalmente oferecem maior retorno (CHEROBIM; ESPEJO, 2011).

A caderneta de poupança é um investimento de renda fixa tradicional e conhecido por seu baixo risco e é muito popular entre os investidores de baixa renda (KERR, 2011).

Quadro 1 - Principais alternativas de investimento - pessoa física

\begin{tabular}{|l|l|}
\hline \multicolumn{1}{|c|}{ Rendimento } & \multicolumn{1}{|c|}{ Produto de investimento } \\
\hline \multirow{4}{*}{ Renda fixa } & Caderneta de poupança \\
\cline { 2 - 2 } & Fundos de Investimento DI, Renda Fixa e Cotas de Fundos \\
\cline { 2 - 2 } & Aplicações em Papéis da dívida pública do Governo - Tesouro Direto \\
\cline { 2 - 2 } & CDBs - Certificados de Depósitos Bancários \\
\cline { 2 - 2 } & Debêntures \\
\cline { 2 - 2 } & Notas Promissórias \\
\hline \multirow{5}{*}{ Renda variável } & Ações \\
\cline { 2 - 2 } & Fundos de Ações \\
\cline { 2 - 2 } & Fundos Multimercado \\
\cline { 2 - 2 } & Fundos Cambiais \\
\hline
\end{tabular}

Fonte: Cherobim e Espejo (2011, p. 95).

Percebe-se que, diante disso, apenas uma minoria das famílias brasileiras consegue controlar e gerenciar seus recursos, sendo que as sobras são destinadas aos mais diversos tipos de investimentos. Entretanto, o maior problema está justamente com a grande parcela de famílias que não consegue gastar menos do que seus rendimentos, gerando um ciclo negativo no mercado, ocasionando uma 'bola de neve' nos negócios. 


\section{Procedimentos metodológicos}

Este estudo, do ponto de vista metodológico, possui caráter quantitativo e descritivo (MALHOTRA, 2006; GIL, 2008). Foram coletados dados entre os meses de abril e junho de 2017, durante a realização das oficinas de Finanças Pessoais, por meio de questionários estruturados que foram aplicados nas escolas de Ensino Médio do Vale do Taquari. Estes, foram aplicados pelos alunos da disciplina de Finanças Pessoais da Universidade do Vale do Taquari - Univates. A aplicação de questionários estruturados caracteriza a pesquisa de caráter quantitativo, onde faz-se o "uso intensivo de modelos matemáticos e dados estatísticos." (CASARIN; CASARIN, 2012, p. 36).

As oficinas foram realizadas em duas etapas, nas quais foram abordados assuntos como receitas, despesas, investimentos, planejamento financeiro pessoal, controle de despesas pessoais, orçamento e fluxo de caixa pessoal, juros, armadilhas que corroem o orçamento familiar, e dicas para enxugar/cortar gastos.

Na primeira etapa, os alunos de Ensino Médio recebiam os questionários e as devidas orientações de como preenchê-los, pois possuíam uma parte a ser respondida na primeira etapa e o restante era preenchido numa outra oportunidade (segunda etapa). Estes questionários abordavam questões como hábitos financeiros, reações em relação às finanças pessoais, ao nível de conhecimento, aos itens que os estudantes desejavam obter mais informações, entre outros. Além disso, os questionários foram elaborados de maneira simples e objetiva para que os estudantes respondessem de acordo com a sua realidade, de forma aberta e dinâmica. Aproximadamente 30 dias posterior à realização da primeira etapa, foi realizada a segunda etapa da oficina, em que os alunos respondiam em relação à avaliação do curso, bem como descreviam seus hábitos após as oficinas.

A amostra não-probabilística, obtida por acessibilidade durante as oficinas realizadas (BARROS; LEHFELD, 2000), totalizou 470 alunos respondentes na primeira etapa da oficina e 330 na segunda etapa.

Após a coleta dos questionários, as respostas foram digitadas em uma planilha eletrônica, o que permitiu a elaboração de tabelas de frequências e a elaboração de gráficos, subsidiando as análises e as conclusões do estudo.

Os resultados do levantamento realizado com alunos de Ensino Médio do Vale do Taquari consistiram, primeiramente, na identificação do perfil dos respondentes; na sequência, 
os hábitos e os conhecimentos financeiros, e, por último, as ações adotadas após a participação dos alunos na primeira etapa da oficina de Finanças Pessoais.

O presente estudo envolveu 30 estudantes de graduação que ministraram 16 oficinas com o tema Finanças Pessoais em 13 escolas de 10 municípios do Vale do Taquari, destas escolas, 11 (84,62\%) eram públicas e $2(15,38 \%)$ eram particulares. Participaram das oficinas 470 alunos de Ensino Médio, cuja maioria possuía entre 16 e 18 anos de idade, sendo 170 $(29,8 \%)$ alunos com 16 anos; $231(49,1 \%)$ com 17 anos e 59 (12,6\%) com 18 anos, os demais possuíam 15, 19, 20 ou 21 anos.

A maior parte dos alunos têm origem alemã ou italiana, sendo 43,11\% de origem alemã e $34,95 \%$ de origem italiana, as demais origens identificadas foram portuguesa, africana e espanhola, respectivamente. Dos alunos que participaram das oficinas, 88,68\% afirmam que nas suas casas residem 3, 4 pessoas ou mais, e apenas 11,32\% residem com apenas 1 pessoa.

Do total de respondentes, $85,11 \%$ recebem mesada e $57,87 \%$ possui uma fonte de renda própria, como trabalho ou estágio. Outro fator importante a saber é que $300(63,83 \%)$ alunos não tiveram nenhuma aula, cujo conteúdo estivesse relacionado à educação financeira pessoal na escola. No entanto, concordando com o que afirma Meneghetti Neto (2014), 94,26\% de todos os alunos entrevistados acreditam que o momento adequado para o aprendizado sobre educação financeira seria no Ensino Médio.

\section{Hábitos financeiros e conhecimentos no tema dos alunos}

Quando perguntado aos alunos quais os hábitos financeiros que eles praticavam, dentre as opções de resposta a que teve o maior número de citações foi "planeja as finanças para o futuro" $(28,53 \%)$. Os alunos assinalaram que controlam o dinheiro que recebem $(22,91 \%)$ e também que possuem caderneta de poupança $(19,73 \%)$. 17,30\% das assinalações foram na opção "gasta tudo o que recebe", mostrando que apenas uma pequena parcela dos alunos não guarda nada do que recebe da sua mesada/estágio/trabalho, conforme Tabela 1. 
Tabela 1 - Hábitos financeiros que os alunos praticam

\begin{tabular}{lcc}
\hline Opções de resposta & $\mathbf{N}$ & $\mathbf{\%}$ \\
\hline Planeja as finanças para o futuro & 188 & $28,53 \%$ \\
Controla o dinheiro que recebe & 151 & $22,91 \%$ \\
Tem caderneta de poupança & 130 & $19,73 \%$ \\
Gasta tudo o que recebe & 114 & $17,30 \%$ \\
Tem dinheiro investido & 76 & $11,53 \%$ \\
\hline Total & 659 & $100,00 \%$ \\
\hline
\end{tabular}

Fonte: Resultado da pesquisa (2017).

De acordo com a Tabela 2, a grande maioria dos alunos $(98,51 \%)$ acreditava que possuía pouco ou regular conhecimento em finanças pessoais antes da $1^{\mathrm{a}}$ etapa da oficina. Além disso, 3 alunos $(0,64 \%)$ acreditavam que não possuíam nenhum conhecimento no tema e nenhum aluno possuía total conhecimento.

Tabela 2 - Nível de conhecimento em finanças pessoais antes da $1^{\circ}$ etapa da oficina

\begin{tabular}{lcc}
\hline Opções de resposta & $\mathbf{N}$ & \% \\
\hline Pouco & 295 & $62,77 \%$ \\
Regular & 168 & $35,74 \%$ \\
Nenhum & 3 & $0,64 \%$ \\
Muito & 0 & $0,00 \%$ \\
Não responderam & 4 & $0,85 \%$ \\
\hline Total & 470 & $100,00 \%$ \\
\hline
\end{tabular}

Fonte: Resultado da pesquisa (2017).

Esta tabela mostra que os índices de endividamento apresentados anteriormente são, principalmente, resultados de pouco conhecimento em finanças pessoais, conforme dados do BCB (2013), visto que a maioria dos estudantes possui pouco conhecimento.

Quanto aos conhecimentos sobre o tema, os alunos foram questionados sobre quais itens acreditavam possuir conhecimento para tomar decisões. Conforme a Tabela 3, a maioria das citações $(19,34 \%)$ aponta que os alunos acreditam possuir informações para tomar decisões sobre a poupança, o que concorda com Kerr (2011). A Tabela 3 também mostra que a segunda opção mais assinalada foi "nenhum dos itens", mostrando que o número de alunos que acreditam não possuir conhecimento sobre nenhum item também é significativo. A bolsa de valores é o item que recebeu menos marcações, apenas 0,93\% das 755 citações. 
Tabela 3 - Itens que os alunos acreditam ter informações suficientes para tomar decisões

\begin{tabular}{lcc}
\hline Opções de resposta & $\mathbf{N}$ & $\mathbf{\%}$ \\
\hline Poupança & 146 & $19,34 \%$ \\
Nenhum dos itens & 129 & $17,09 \%$ \\
Uso do cartão de crédito & 117 & $15,50 \%$ \\
Juros & 80 & $10,60 \%$ \\
Gerenciamento de gastos & 77 & $10,20 \%$ \\
Consumo planejado & 68 & $9,01 \%$ \\
Aposentadoria & 46 & $6,09 \%$ \\
Empréstimos pessoais & 45 & $5,96 \%$ \\
Financiamentos & 40 & $5,30 \%$ \\
Bolsa de valores & 7 & $0,93 \%$ \\
\hline Total & 755 & $100,00 \%$ \\
\hline
\end{tabular}

Fonte: Resultado da pesquisa (2017).

Conforme o Gráfico 1, pode-se identificar a frequência com que os alunos praticam determinados hábitos financeiros, como poupar dinheiro com a intenção de comprar um produto mais caro, comparar preços antes de realizar a compra e pensar em investir o dinheiro. A maioria dos alunos $(48,32 \%)$ economiza dinheiro visando, quase sempre, a compra de algo de maior valor; mais de $50 \%$ dos alunos sempre comparam preço ao fazer compras e apenas $3 \%$ dos alunos relataram que nunca pensam em investir seu dinheiro.

Gráfico 1 - Outros hábitos financeiros praticados pelos estudantes do Ensino Médio

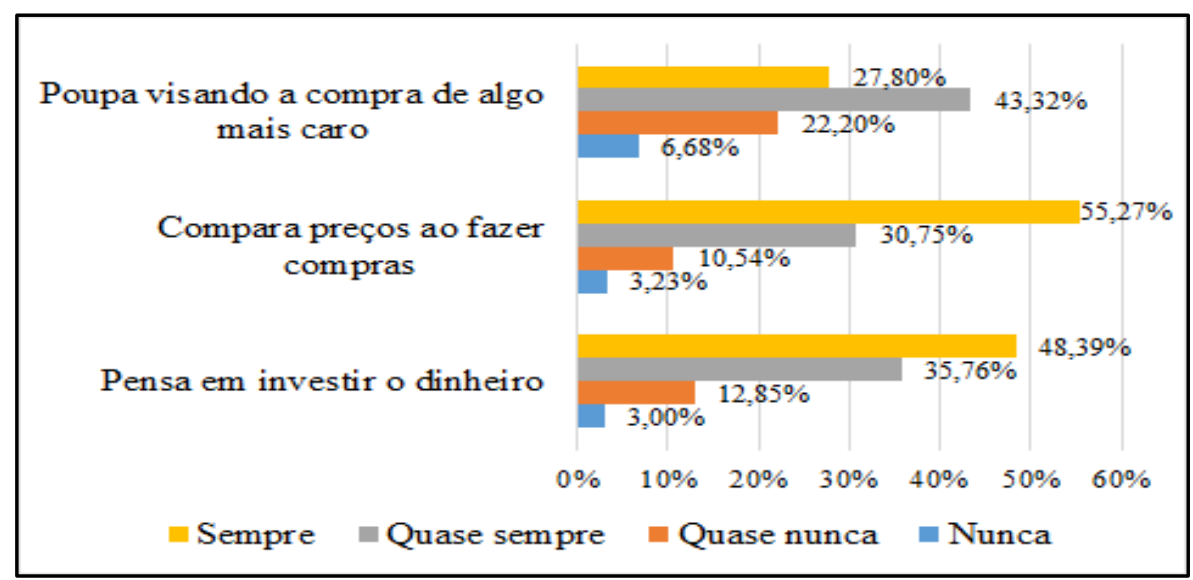

Fonte: Resultado da pesquisa (2017). 
Embora poucos alunos realizem o controle mensal de suas finanças, a maioria dos alunos $(88,3 \%)$ considera importante ter uma vida financeira saudável, e o número de estudantes que pensa em se tornar financeiramente independente de seus responsáveis o mais rápido possível é expressivo, visto que 297 alunos (63,2\%) responderam sempre e $129(27,4 \%)$ responderam quase sempre nesta pergunta.

Ainda relacionado aos hábitos financeiros, apenas 51 alunos (10,9\%) afirmaram que sempre ou quase sempre compram o querem e sem limites de gastos. Além disso, 58 alunos $(12,3 \%)$ relataram que sempre ou quase sempre seus gastos mensais ultrapassam o valor recebido no período.

\section{Ações adotadas após as oficinas de Finanças Pessoais}

Os questionários aplicados possuíam também questões em que os alunos relataram quais hábitos relacionados às finanças pessoais haviam adotado após as oficinas que foram realizadas através do projeto de extensão Educação Empreendedora e Financeira, da Univates.

Observando o Gráfico 2, os alunos responderam que após o $1^{\circ}$ momento da oficina, passaram a fazer planos para o futuro e também a poupar dinheiro. Os alunos procuraram consumir apenas o necessário, evitando desperdícios, e outro ponto importante a destacar refere-se à adoção do controle das finanças, o que corrobora com Massaro (2015).

Gráfico 2 - Atitudes adotadas após as oficinas de Finanças Pessoais

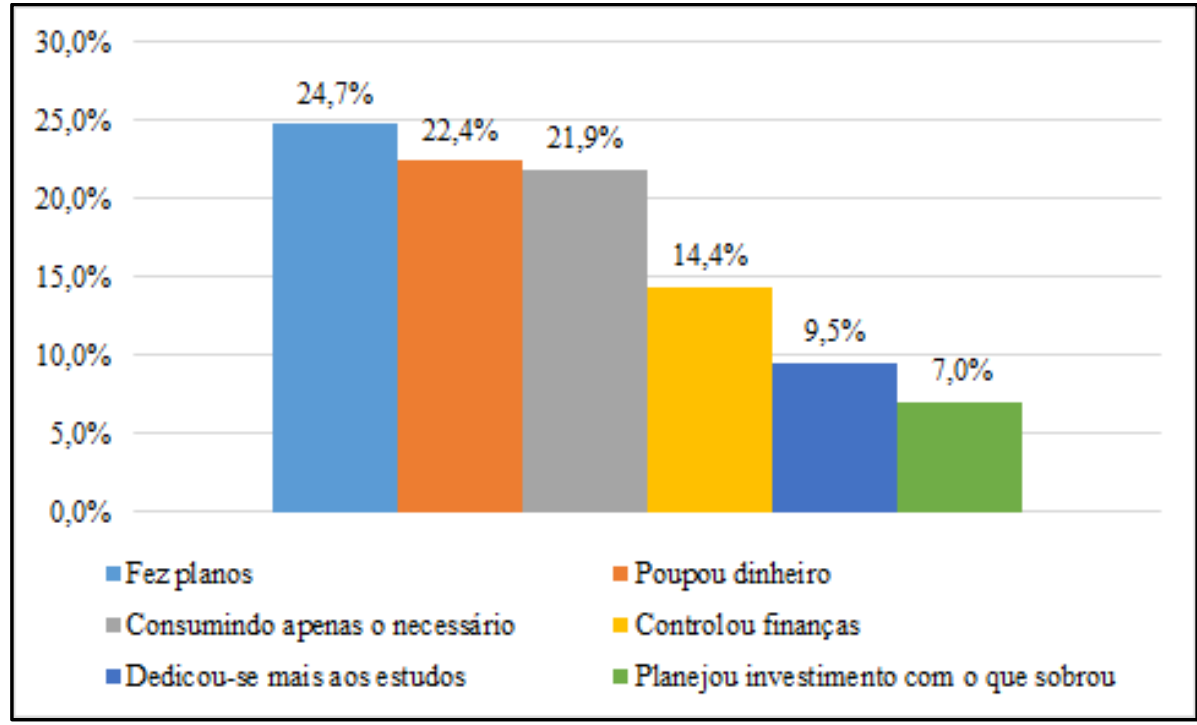

Fonte: dados da pesquisa (2017). 
Os alunos afirmaram que desejam continuar poupando dinheiro $(21,4 \%)$; fazer planos para o futuro $(17,7 \%)$; continuar os estudos $(16,5 \%)$; consumir somente o necessário $(16,4 \%)$; controlar suas finanças $(15,4 \%)$ e planejar novos investimentos com o dinheiro que sobrar $(12,4 \%)$, ou seja, diminuindo o despreparo individual citado por Domingos (2011).

Aos alunos também foi solicitado que indicassem o nível de conhecimento no tema antes e após as oficinas. Antes das oficinas, 48,5\% possuíam pouco conhecimento; 42,1\% possuíam regular conhecimento; 6,6\% não possuíam nenhum conhecimento e $2,8 \%$ assinalou possuir muito conhecimento. Já, após as oficinas, 87,9\% dos alunos possuíam regular ou muito conhecimento (sendo 55,2\% conhecimento regular e 32,7\% muito conhecimento); apenas 7,3\% dos alunos acreditavam ter pouco conhecimento e 4,2\% assinalaram que possuíam total conhecimento.

Assim, a percepção é de que as oficinas de Finanças Pessoais atingiram o objetivo enquanto mecanismo para a promoção de conhecimento sobre a temática. A adoção de ações por parte dos alunos que assistiram às oficinas demonstra que estas iniciativas devem ser repetidas e ampliadas, sob o argumento que quanto mais as famílias tiverem ciência das suas limitações financeiras, melhor será o ambiente de negócios no país, impactando diretamente na qualidade de vida das pessoas e na sobrevivências das organizações.

\section{Conclusões}

Este trabalho buscou analisar o comportamento financeiro dos jovens que estão frequentando o Ensino Médio no Vale do Taquari - RS. Constatou-se que a maioria dos jovens possui conhecimentos básicos sobre finanças pessoais e também apresenta alguns hábitos financeiros relevantes. Entretanto, os hábitos financeiros são ainda poucos, tendo, portanto, a necessidade de aprimorar os conhecimentos dos alunos.

Conforme observado na literatura, atualmente, os jovens são muito otimistas e pouco se preocupam em guardar algum valor para o futuro, e isto pode ser validado quando analisamos que, a maioria deseja ser independente financeiramente, o mais rápido possível, de seus responsáveis, porém mais de $60 \%$ dos alunos nunca ou quase nunca controlam suas finanças. Além disso, mais de $80 \%$ dos alunos entrevistados recebem mesada; mais da metade dos alunos possui uma fonte de renda própria, porém apenas aproximadamente $20 \%$ possuem caderneta de poupança, que é o investimento mais acessível e popular dos brasileiros. 
Poucos alunos reportaram que os gastos mensais não possuem limite ou que deixam de pagar alguma conta e a maioria planeja suas finanças para o futuro, embora não tome nota dos seus ganhos e gastos. Assim, vê-se a oportunidade de enriquecer o conhecimento destes alunos, através das oficinas realizadas, estimulando-os a poupar, indicando planilhas de controles, bem como alertando-os para eventuais armadilhas que podem corroer o orçamento de uma família.

Pode-se concluir também que, não só a literatura, mas também os próprios alunos percebem que o Ensino Médio seria o momento ideal para se tratar da educação financeira, afinal, os jovens estão entrando no mercado de trabalho e estão ansiosos para começar sua vida independente de seus responsáveis. Assim, os jovens teriam a oportunidade de aprender e colocar em prática, aos poucos, tais conhecimentos, já que ainda moram com os pais e caso ocorressem deslizes, os responsáveis poderiam auxiliar, e quando os jovens tiverem suas próprias casas e famílias, poderão administrar suas finanças de maneira correta.

Por fim, as oficinas de Finanças Pessoais como as oferecidas pelo projeto de extensão Educação Empreendedora e Financeira, da Univates, são muito valiosas para os alunos, pois oferecem informações e são o primeiro contato com o tema, visto que a grande maioria não teve nenhuma aula cujo assunto estivesse relacionado com as finanças pessoais.

\section{Referências}

ANDERSSON, Pedro. Contas poupança. Lisboa: Contraponto, 2016.

BANCO CENTRAL DO BRASIL. Caderno de Educação Financeira: Gestão de Finanças Pessoais. Brasília: Banco Central do Brasil, 2013. E-book. Disponível em: https://www.bcb.gov.br/pre/pef/port/caderno_cidadania_financeira.pdf. Acesso em: 19 set. 2017.

BARROS, Aidil J. da Silveira; LEHFELD, Neide A. de Souza. Fundamentos de metodologia científica: um guia para a iniciação científica. São Paulo: Makron Books, 2000.

BRUHN, Mirian; LEÃO, Luciana de Souza; LEGOVINI, Arianna; MARCHETTI, Rogelio; ZIA, Bilal. The impact of high school financial education: experimental evidence from Brazil. Policy Research Working Paper 6723. World Bank. 2017. Disponível em: http://documents.worldbank.org/curated/en/753501468015879809/pdf/WPS6723.pdf. Acesso em: 12 dez. 2017.

CASARIN, Helen de Castro Silva; CASARIN, Samuel José. Pesquisa científica: da teoria à prática. Curitiba: InterSaberes, 2012. 
CHEROBIM, Ana Paula Mussi Szabo; ESPEJO, Márcia Maria dos Santos Bortolocci. Finanças pessoais: conhecer para enriquecer. 2 ed. São Paulo: Atlas, 2011.

COMITÊ NACIONAL DE EDUCAÇÃO FINANCEIRA (CONEF). Educação financeira nas escolas: ensino médio: livro do professor. Brasília: CONEF, 2013. E-book. Disponível em: http://issuu.com/edufinanceiranaescola/docs/livro-aluno-bloco1?e=11624914/49399073. Acesso em: 19 set. 2017.

CONFEDERAÇÃO NACIONAL DO COMÉRCIO DE BENS, SERVIÇOS E TURISMO (CNC). Pesquisa Nacional de Endividamento e Inadimplência do Consumidor (PEIC). 2017. Disponível em:

http://cnc.org.br/sites/default/files/arquivos/analise_peic_fevereiro2017.pdf. Acesso em: 12 dez. 2017.

DOMINGOS, Reinaldo. Livre-se das dívidas: como equilibrar as contas e sair da inadimplência. São Paulo: DSOP Educação Financeira, 2011.

FERREIRA, Roberto G. Matemática financeira aplicada: mercado de capitais, administração financeira, finanças pessoais. 6. ed. São Paulo: Atlas, 2008.

GIL, Antonio Carlos. Métodos e técnicas de pesquisa social. 6. ed. São Paulo: Atlas, 2008.

GITMAN, Lawrence J.; JOEHNK, Michael D. Princípios de investimentos. São Paulo: Pearson Addison Wesley, 2005. E-book. Disponível em: www.univates.br/biblioteca. Acesso em: 18 out. 2017.

GITMAN, Lawrence J. Princípios de Administração Financeira - Essencial. 2. ed. Porto Alegre: Bookman, 2001.

GODOY, José; MEDINA, Luiz Gustavo; GAZAL, Marco Antônio Jr. Investindo sem erro: dinheiro protegido, futuro garantido. São Paulo: Saraiva, 2006.

KERR, Roberto Borges. Mercado financeiro e de capitais. São Paulo: Pearson Prentice Hall, 2011. E-book. Disponível em: www.univates.br/biblioteca. Acesso em: 26 set. 2017.

LUQUET, Mara; ASSEF, Andrea (org.). Você tem mais dinheiro do que imagina: um guia para suas finanças pessoais. São Paulo: Saraiva, 2006.

LUQUET, Mara; ASSEF, Andrea. Meninas normais vão ao shopping, meninas iradas à Bolsa. 2. ed. São Paulo: Saraiva. 2007.

MALHOTRA, Naresh K. Pesquisa de marketing: uma orientação aplicada. 4. ed. Porto Alegre: Bookman, 2006.

MASSARO, André. Como cuidar de suas finanças pessoais. Brasília: Conselho Federal de Administração, 2015. E-book. Disponível em: http://www.cfa.org.br/servicos/publicacoes /cfa-cartilha-financa-pessoal.pdf. Acesso em: 19 set. 2017. 
MENEGHETTI NETO, Alfredo (org.). Educação financeira. Porto Alegre: EDIPUCRS, 2014. E-book. Disponível em: www.univates.br/biblioteca. Acesso em: 19 set. 2017.

PESQUISA de Endividamento e Inadimplência do Consumidor (PEIC). Fecomércio RS, Porto Alegre, 6 set. 2017. Disponível em: http://fecomercio-rs.org.br/wpcontent/uploads/2017/03/analisePEICago17.pdf. Acesso em: 19 set. 2017.

PIRES, Valdemir. Finanças pessoais fundamentos e dicas. Piracicaba: Equilíbrio, 2006.

SAVOIA, José Roberto Ferreira; SAITO, André Taue; SANTANA, Flávia de Angelis.

Paradigmas da educação financeira no Brasil. Revista de Administração Pública, Rio de Janeiro, v. 41, n. 6, nov./dez. 2007. Disponível em:

SPC BRASIL. Serviço de Proteção ao Crédito. 2017. Disponível em:

https://www.spcbrasil.org.br/pesquisas/indice/3130. Acesso em: 10 nov. 2017.

Recebido em: 20 de junho de 2018.

Aceito em: 9 de dezembro de 2020. 